\title{
Characterization and in vitro evaluation of seaweed species as potential functional ingredients to ameliorate metabolic syndrome
}

\author{
Daniel Rico ${ }^{\mathrm{a}}$, Ana Belén Martín Diana ${ }^{\mathrm{a}}$, Iñaki Milton-Laskibar ${ }^{\mathrm{b}, \mathrm{c}}$, Alfredo Fernández- \\ Quintela $^{\text {b,c }}$, Jose Manuel Silván ${ }^{\mathrm{d}}$, Dilip K. Rai ${ }^{\mathrm{e}}$, Alka Choudhary ${ }^{\mathrm{e}}$, Elena Peñas ${ }^{\mathrm{d}, *}$, Daniel \\ Antonio de Luis ${ }^{\mathrm{f}}$, Cristina Martínez-Villaluenga ${ }^{\mathrm{d}}$
}

${ }^{a}$ Department of Research and Technology, Agrarian Technological Institute of Castilla and Leon (ITACyL), Government of Castilla and Leon, Ctra. de Burgos Km. 119, Valladolid, 47071, Spain

${ }^{b}$ Nutrition and Obesity Group, Department of Nutrition and Food Science, University of the Basque Country (UPV/EHU) and Lucio Lascaray Research Institute, 01006 Vitoria, Spain

${ }^{c}$ CIBERobn Physiopathology of Obesity and Nutrition, Institute of Health Carlos III, 28029 Madrid, Spain

${ }^{\mathbf{d}}$ Department of Food Characterization, Quality and Safety; Institute of Food Science, Technology and Nutrition (ICTAN-CSIC), Juan de la Cierva, 3, 28006 - Madrid, Spain. ${ }^{\mathrm{e}}$ Department of Food Biosciences, Teagasc Food Research Centre Ashtown, Dublin 15, Ireland

${ }^{\mathrm{f}}$ Endocrinology and Nutrition Department, Hospital Clínico Universitario de ValladolidIEN, Facultad de Medicina Universidad de Valladolid, Spain.

\section{*Corresponding author:}

Elena Peñas Pozo

e-mail address: elenape@ictan.csic.es

Telephone: +3491258 7601; Fax: +34915644853 


\section{ABSTRACT}

This study aimed at identifying seaweed species with optimal characteristics to develop multifunctional foods for metabolic syndrome (MetS) management. Mass spectrometry chemical characterization and bioactive profile evaluation of methanolic extracts from seven commonly consumed seaweeds were compared. Monomeric sugars namely mannitol, fucitol, xylitol and their sulphated analogs as well as lipids (phosphatidic acid, octadecenoic acid, and prostaglandin $2 \alpha$ ) were detected in seaweeds. Himanthalia elongata showed the highest phenolic content $(24.04 \mu \mathrm{mol}$ GAE/g), and antioxidant activity. This species was the only one showing angiotensin converting enzyme-I inhibitory activity $\left(\mathrm{IC}_{50}=65 \mu \mathrm{g} / \mathrm{mL}\right)$. U. pinnatifida and $H$. elongata extracts were notably more effective reducing pro-inflammatory molecules in lipopolysaccharide-induced RAW 264.7 macrophages. Finally, Ulva spp., Palmaria palmata, U. pinnatifida and H. elongata significantly inhibited triglyceride accumulation in mature 3T3-L1 adipocytes (43-52\% inhibition). Among seaweeds, H. elongata showed the highest potential to be used as ingredient in the development of new functional foods for MetS management.

Keywords: seaweed, antioxidant; anti-hypertensive; anti-inflammatory; triglyceride accumulation, metabolic syndrome 


\section{Introduction}

The modern lifestyle is leading to changes in the eating patterns of global population towards diets rich in refined sugars, salt, saturated fats and energy-dense foods (Hyseni et al., 2017). These modern diets contribute to the development of chronic diseases responsible for $70 \%$ of all deaths worldwide (WHO, 2017). Metabolic syndrome (MetS) is becoming one of the most important health concerns in the last years, due to its rising prevalence (Grundy, 2016). This syndrome encompasses a constellation of several risk factors including hyperglycemia, raised blood pressure, dyslipidemia and visceral obesity that predispose to the development of cardiovascular disease and type 2 diabetes mellitus (Alberti et al., 2009). According to the National Cholesterol Education Program Adult treatment Panel III (NCEP ATP III, 2002) definition, MetS is present if three or more of the following five criteria are met: waist circumference over $102 \mathrm{~cm}$ (men) or $88 \mathrm{~cm}$ (women), blood pressure over 130/85 $\mathrm{mmHg}$, fasting triglyceride level over $150 \mathrm{mg} / \mathrm{dl}$, fasting high-density lipoprotein (HDL) cholesterol level less than $40 \mathrm{mg} / \mathrm{dl}$ (men) or $50 \mathrm{mg} / \mathrm{dl}$ (women) and fasting blood sugar over $100 \mathrm{mg} / \mathrm{dl}$. Indeed, visceral obesity and insulin resistance are key etiological factors of MetS development. Obesity causes an increased concentration of free fatty acids (FFA) that may cause insulin resistance, oxidative stress and inflammation (Dandona et al., 2005). The search for efficient and economic strategies for prevention of MetS is crucial to ameliorate its impact on global health and economy. Healthy diets may play a key role in reducing the incidence of MetS (Grosso et al., 2017). In this context, many studies have provided evidence on the role of foods rich in bioactive compounds to counteract the different components of MetS.

42 Due to the current consumers trend to embrace organically grown, natural and healthy foods from clean environments, edible macroalgae (seaweed) are receiving an increasing acceptance. Edible seaweeds have been consumed as food and traditional medicines since 
consumption in western societies is lower than in Asia, but they have been traditional consumed in countries such as England, Ireland, Scotland, Scandinavia, and Canada for human and domestic animal feeding (Delaney et al., 2016). The nutritional and beneficial health effects derived from seaweed consumption has stimulated their inclusion as functional ingredients in a broad range of foodstuffs (sushi, pasta, biscuits, bread and beverages, among others), and can be also consumed fresh or dried as whole foods (Rioux, Beaulieu and Turgeon, 2017). Moreover, seaweeds are commonly used in the production of gelling agents such as alginate or agar by the food industry in western countries (Smit 2004). The inclusion of seaweed extracts enriched in different bioactive compounds as powdered ingredients could represent a promising tool for the design of multifunctional foods or nutraceuticals.

Among the eight most important seaweeds used for human consumption are species from Porphyra spp. (Nori), Laminaria japonica (Kombu), Undaria pinnatifida (Wakame), Ulva spp. (Sea Lettuce), Palmaria palmata (Dulse) and Chondrus crispus (Irish moss) (Hassan, 2009). They are attracting growing interest nowadays as excellent sources of essential fatty acids with a nutritionally ideal n-6/n-3 fatty acid ratio, polysaccharides, with relatively high protein content, including all the essential amino acids, minerals, vitamins and trace elements. In addition, several in vivo studies support the positive effect of seaweed products when consumed directly or as dietary supplements on health by reducing body weight (Okada et al., 2011), lipid oxidation (Grasa-López et al., 2016), oxidative stress and insulin resistance (Tong et al., 2015). Seaweed extracts have also shown antimicrobial (Cox, Abu-Ghannam, \& Gupta, 2010), anti-inflammatory (Han et al., 2015), anti-diabetic (Kang et al., 2013) and prebiotic effects (Charoensiddhi et al., 2017). All these effects have been attributed to the presence of bioactive compounds such as polysaccharides, bioactive lipids, trace elements and phenolic compounds (Gupta \& Abu-Ghannam, 2011). 
All these characteristics suggest a promising potential to develop novel seaweed products with commercial interest for functional food applications to enhance human health (Murray, Dordevic, Ryan, \& Bonham, 2017). For this purpose, consideration must be given to the selection of seaweed species with the best phytochemical and bioactivity profile. Different algal species contain varying combinations and concentrations of bioactive compounds and bioactive properties (Murray et al., 2017). To date there is no research that has examined and compared the potential of different seaweeds with the aim to develop multifunctional food products for amelioration of MetS progression. Therefore, the aim of the present study was to chemically characterize seven seaweed species and to evaluate their potential for in vitro antihypertensive, anti-inflammatory, antioxidant and triacylglyceride-lowering activities.

\section{Materials and methods}

\subsection{Chemicals}

Dimethyl sulfoxide (DMSO), lipopolysaccharide (LPS) from Escherichia coli O5:B55, Folin-Ciocalteau phenol reagent, Trolox, 2,2-diphenyl-1-picrylhydrazyl (DPPH), fluorescein, 2,2'-azobis (2-methyl-propionamidine dihydrochloride) (AAPH), captopril and 3,4,5-dimethylthiazol-2,5-diphenyl-tetrazolium bromide (MTT) were purchased from SigmaAldrich (St. Louis, MO, USA). Dulbecco's Modified Eagle's Medium (DMEM), penicillin/streptomycin $(5,000 \mathrm{U} / \mathrm{mL})$, and phosphate buffer saline (PBS) were purchased from Lonza (Cultek S.L.U, Madrid, Spain). Fetal bovine serum (FBS) of South American origin was obtained from Fisher Scientific (Madrid, Spain). Cell culture flasks and plates were obtained from Sarstedt (Nümbrecht, Germany).

\subsection{Sample material}

Seaweed species Porphyra spp. (Nori), Undaria pinnatifida (Wakame), Ulva spp. (Sea lettuce), Himanthalia elongata (Sea thong), Chondrus cripus (Irish moss), Laminaria 
ochroleuca (Kombu), and Palmaria palmata (Dulse) were collected and provided by a local

95 producer (Portomuiños; Galicia, Spain). Fresh raw materials were lyophilized and powdered using a grinding mill and kept at $-80^{\circ} \mathrm{C}$ until further analysis.

\subsection{Preparation of methanolic extracts}

Seaweed extraction was carried out using $1 \mathrm{~g}$ of powdered sample and homogenized in $2 \times 10 \mathrm{~mL}$ of $50 \%$ aqueous methanol by magnetic stirring for $1 \mathrm{~h}$. The two extracts were centrifuged at $1,635 \mathrm{x} g$ for $10 \mathrm{~min}$ at $4{ }^{\circ} \mathrm{C}$. Supernatants were combined and filtered using Whatman Grade 1 filter paper. Filtrates were evaporated under reduced pressure (SpeedVac Concentrator, Thermo Fisher Scientific, Madrid, Spain) to remove solvent and held at $-80^{\circ} \mathrm{C}$ until analysis. For all cell assays, samples were reconstituted in free-serum cell culture media to the appropriate concentration for testing.

\subsection{Liquid chromatography-tandem mass spectrometry (LC-MS/MS)}

LC-MS/MS analysis of the seaweed extracts were performed on a Q-Tof Premier mass spectrometer (Waters Corporation, Milford, MA, USA) coupled to an Alliance 2695 HPLC system (Waters Corporation, Milford, MA, USA). Separation of compounds was achieved on an Atlantis T3 C18 column (Waters Corporation, Milford, USA, $100 \mathrm{~mm}$ x $2.1 \mathrm{~mm} ; 3 \mu \mathrm{m}$ particle size) using $0.1 \%$ aqueous formic acid (solvent $\mathrm{A}$ ) and $0.1 \%$ formic acid in acetonitrile (solvent B). Column temperature was maintained at $40{ }^{\circ} \mathrm{C}$. A stepwise gradient from $10 \%$ to $90 \%$ solvent B was applied at a flow rate of $0.3 \mathrm{~mL} / \mathrm{min}$ for $18 \mathrm{~min}$. Electrospray mass spectra data recorded on a negative ionisation mode for a mass range $\mathrm{m} / z 100$ to $\mathrm{m} / \mathrm{z} 1000$. Capillary voltage and cone voltage were set at $3 \mathrm{kV}$ and $30 \mathrm{~V}$, respectively. Collision induced fragmentation (CID) of the analytes was achieved using $12 \mathrm{eV}$ to $20 \mathrm{eV}$ energy with argon as the collision gas.

\subsection{Total phenolic content}


Folin-Ciocalteu method (Slinkard, 1977) was used with slight modifications. A volume of $140 \mu \mathrm{L}$ of the sample extract was mixed with $280 \mu \mathrm{L}$ of Folin-Ciocalteu reagent previously diluted $(1: 10, \mathrm{v} / \mathrm{v})$ and $980 \mu \mathrm{L}$ of $42.86 \mathrm{mM}$ sodium carbonate. The mixture was shaken and allowed to stand for 100 min in darkness, following centrifugation at $15,000 \times \mathrm{g}$ for $3 \mathrm{~min}$. The absorbance was measured at $760 \mathrm{~nm}$ with a microplate reader (Fluostar Omega, BMG Ortenberg, Germany). Results were expressed as mg gallic acid equivalents (GAE)/g of sample.

\subsection{Antioxidant activity of seaweed and seaweed extracts}

Antioxidant activity was measured in extracts using different assays: DPPH radical scavenging activity (DPPH), Oxygen Radical Absorbance Capacity (ORAC), FRAP (Ferric Reducing Ability of Plasma) and Trolox Equivalent Antioxidant Capacity (TEAC). In addition, total antioxidant activity was measured in samples without any extraction procedure (direct method) by the DPPH and TEAC methods.

DPPH was evaluated according to the procedure described by Brand-Williams et al. (1995) with modifications. A total of $0.1 \mathrm{~mL}$ of extract was added to $3.9 \mathrm{~mL}$ of $63.41 \mu \mathrm{M}$ DPPH methanolic solution. Absorbance was measured at $515 \mathrm{~nm}$ using a microplate reader (Fluostar Omega) for $60 \mathrm{~min}$. Eight different concentrations $(0.9-0.12 \mathrm{mM})$ of Trolox were used to make the calibration curve. Results were expressed as inhibition percentage (\%).

FRAP was determined according to a procedure described earlier (Pereira et al., 2008). 137 Results were expressed as $\mu$ mol Fe equivalent/g of sample.

ORAC was performed as described previously (Ou, Hampsch-Woodill, \& Prior, 139 2001). A volume of $150 \mu \mathrm{L}$ fluorescein was placed in a 96-well black polystyrene plate, and $14025 \mu \mathrm{L}$ of Trolox standard, sample or phosphate buffer as blank were added, all in duplicates. 141 Samples, standards and blanks were incubated with fluorescein at $37^{\circ} \mathrm{C}$ for 3 min before 142 AAPH solution was added to initiate the oxidation reaction. Fluorescence was monitored over 
$14335 \mathrm{~min}$ with a microplate reader (Fluostar Omega), using $485 \mathrm{~nm}$ excitation and $528 \mathrm{~nm}$ 144 emission filters. Results were calculated using the areas under the fluorescein decay curves, 145 between the blank and the sample, and were expressed as mmol Trolox Equivalents (TE)/g of 146 sample.

TEAC analysis was used to evaluate the antioxidant capacity of the samples in a direct 148 way, without extraction, as described earlier (Serpen, Capuano, Fogliano, \& Gökmen, 2007). 149 Ten milligrams of solid sample was mixed with $160 \mathrm{~mL}$ of ethanol:water $(50: 50, \mathrm{v}: \mathrm{v})$. After, $1501.6 \mathrm{~mL}$ ABTS solution was added to the sample. The mixture was incubated at $350 \mathrm{rpm}$ 151 during 30 min (Thermomixer Compact, Eppendorf, AG, Hamburg, Germany). Then, the 152 sample was centrifuged at $15,330 \mathrm{x} g$ during $2 \mathrm{~min}$. The absorbance was measured at $730 \mathrm{~nm}$ 153 with a microplate reader (Fluostar Omega,). Results were expressed as mg TE/g of sample.

154 2.7. Anti-hypertensive activity

155 ACE-inhibitory activity was performed as reported earlier (Shalaby, Zakora, \& Otte, 2006). 156 N-[3-(2-Furyl) acryloyl]-L-phenylalanyl-glycylglycine (FA-PGG) was dissolved at a 157 concentration of $1.75 \mathrm{mmol} / \mathrm{L}$ in $50 \mathrm{mmol} / \mathrm{L}$ Tris- $\mathrm{HCl}$ buffer $(\mathrm{pH} 7.5)$ containing $0.3 \mathrm{~mol} / \mathrm{L}$ $158 \mathrm{NaCl}$. ACE solution of 0.25 units $/ \mathrm{mL}$ was freshly prepared by adding $1 \mathrm{~mL}$ of purified water 159 to a vial containing 0.25 units of enzyme. The assay was performed in a 96-well, clear, flat160 bottomed polystyrene plate (Fluostar Omega). First, $10 \mu \mathrm{L}$ of ACE solution and $10 \mu \mathrm{L}$ of 161 sample were placed in each well at room temperature. With an eight-channel pipette, $150 \mu \mathrm{L}$ 162 of preheated $\left(37^{\circ} \mathrm{C}, 15 \mathrm{~min}\right)$ substrate solution (FA-PGG) was added to each well to start the 163 reaction. The microtiter plate was immediately transferred to a PowerWave microplate reader 164 (BioTek, Winooski, VT, USA). The enzyme activity at $37^{\circ} \mathrm{C}$ was based on the initial linear 165 rate of change in absorbance at $340 \mathrm{~nm}$, recorded every $3 \mathrm{~min}$ for $30 \mathrm{~min}$. Captopril was used 166 as a positive inhibitor for ACE at a concentration of $0.32 \mu \mathrm{mol} / \mathrm{L}$. The ACE activity was 
167 calculated as the slope of the decrease in absorbance at $340 \mathrm{~nm}(\rho \mathrm{A})$ and results expressed as $168 \quad \mathrm{IC}_{50}(\mathrm{mg} / \mathrm{mL})$.

169 2.8. Anti-inflammatory activity

170 Murine macrophage cell line RAW 264.7 (American Type Culture Collection, 171 Rockville, MD, USA) was grown in high-glucose DMEM supplemented with 10\% FBS and $1721 \%$ penicillin/streptomycin $(5,000 \mathrm{U} / \mathrm{mL})$ and maintained at a subconfluent density at $37{ }^{\circ} \mathrm{C}$ 173 under $5 \% \mathrm{CO}_{2} / 95 \%$ air atmosphere in a humidified incubator. All experiments were carried 174 out between passage 4 and passage 15 to ensure cell uniformity and reproducibility. For 175 inflammatory experiments, cells were seeded at a density of $5 \times 10^{4}$ cells/well in 96 -well plates 176 and allowed to grow overnight. The cells were pretreated with algae extracts $(1-500 \mu \mathrm{g} / \mathrm{mL})$ 177 dissolved in serum-free medium for $24 \mathrm{~h}$. Then, the medium was removed and cells were 178 washed with PBS and elicited with $10 \mu \mathrm{g} / \mathrm{mL}$ LPS dissolved in serum-free medium for an 179 additional $24 \mathrm{~h}$ period. Finally, the media were collected and nitric oxide (NO) production, 180 tumor necrosis factor $\alpha(\mathrm{TNF}-\alpha)$ and prostaglandin $(\mathrm{PG}) \mathrm{D}_{2}$ detection were carried out.

181 The cytotoxic effect of algae extracts on RAW 264.7 cells was studied. Cell viability 182 was determined by using the MTT reduction assay. After cell treatments, culture medium was 183 removed, cells were washed with PBS and $200 \mu \mathrm{L}$ of serum-free medium were added to each 184 well. Thereafter, $20 \mu \mathrm{L}$ of a MTT solution in PBS $(5 \mathrm{mg} / \mathrm{mL})$ was added to each well and the 185 plates were incubated at $37{ }^{\circ} \mathrm{C}, 5 \% \mathrm{CO}_{2} / 95 \%$ air atmosphere for $2 \mathrm{~h}$. Culture media was 186 aspirated and intracellular formazan crystals were solubilized using $200 \mu \mathrm{L}$ of DMSO. 
Nitrite accumulation, an indicator of NO synthesis, was measured in the culture medium by Griess reaction according to a previously described method (González-Montoya et al., 2018). Briefly, $100 \mu \mathrm{L}$ of DMEM were plated in 96-well plate and an equal amount of Griess reagent constituted by $1 \%(\mathrm{w} / \mathrm{v})$ sulfanilamide and $0.1 \%$ (w/v) N-1-(naphthyl) ethylenediamine-di $\mathrm{HCl}$ in $2.5 \%(\mathrm{v} / \mathrm{v}) \mathrm{H}_{3} \mathrm{PO}_{4}$, was added. The plate was incubated for $5 \mathrm{~min}$ and the absorbance measured at $550 \mathrm{~nm}$ in a microplate reader (BioTek). The amount of NO was calculated using a sodium nitrite standard curve $(0.25-10 \mu \mathrm{g} / \mathrm{mL})$.

For TNF- $\alpha$ analysis, a sandwich enzyme-linked immunosorbent assay (ELISA) kit (Diaclone SAS, Besancon Cedex, France) was used. Briefly, 96-well plates were coated with TNF- $\alpha$ according to the manufacturer's instructions. Diluted biotinylated anti-TNF- $\alpha$ samples were added and incubated at room temperature for $3 \mathrm{~h}$. After washing twice, streptavidinHRP was added and incubated for 30 min. 3,3',5,5'-tetramethylbenzidine (TMB) substrate was added to each well and incubated at room temperature for 12-15 min and the reaction was stopped by adding stop solution. The plate was read at $450 \mathrm{~nm}$ in a Synergy HT microplate reader (BioTek). TNF- $\alpha$ in culture medium was determined using the linear range of a standard curve $(31.25-1,000 \mathrm{pg} / \mathrm{mL})$ and expressed in $\mathrm{pg} / \mathrm{mL}$.

$\mathrm{PGD}_{2}$ levels were determined using a prostaglandin $\mathrm{D}_{2}$ ELISA (Cayman Chemical, Ann Arbor, Michigan, USA) according to the manufacturer's instructions. Plate was read at a wavelength of $405 \mathrm{~nm}$ using a Synergy HT microplate reader (BioTek). $\mathrm{PGD}_{2}$ concentrations in samples from treated cell cultures were determined using the linear range of a standard curve. $\mathrm{PGD}_{2}$ in culture medium was determined using the linear range of a standard curve $(19.5-2,500 \mathrm{pg} / \mathrm{mL})$ and expressed in $\mathrm{pg} / \mathrm{mL}$.

\subsection{Triacylglycerol-lowering activity}


In order to study the cytotoxic effects of the seaweed extracts in mature adipocytes, 3T3-L1 pre-adipocytes (American Type Culture Collection) were cultured in DMEM containing 10\% Fetal Bovine Serum (FBS) (HyClone laboratories, South Logan, UT, USA). Two days after the adipocytes reached confluence (day 0), the cells were stimulated to differentiate for 2 days with DMEM containing $10 \%$ FCS, $10 \mu \mathrm{g} / \mathrm{mL}$ insulin, $0.5 \mathrm{mM} 3-$ isobutyl-1-methylxanthine, and $1 \mu \mathrm{M}$ dexamethasone. From day 4, differentiation medium was replaced by $10 \% \mathrm{FBS} / \mathrm{DMEM}$ medium containing $0.2 \mu \mathrm{g} / \mathrm{mL}$ insulin, and changed every two days until the cells were harvested. All media contained 1\% penicillin/streptomycin $(10,000 \mathrm{U} / \mathrm{mL})$, and the media for differentiation and maturation contained $1 \%(\mathrm{v} / \mathrm{v})$ of biotin and pantothenic acid. Cells were maintained at $37{ }^{\circ} \mathrm{C}$ in a humidified $5 \% \mathrm{CO}_{2}$ atmosphere.

Once the cells reached the day 8 after differentiation, the mature adipocytes were grown in 6-well plates and incubated with insulin-free medium containing either $0.1 \%$ ethanol (control group) or seaweed extracts at $0.05,0.1$ and $0.5 \mathrm{mg} / \mathrm{mL}$ for $24 \mathrm{~h}$. Then, cell viability was determined by the neutral red assay TOX-4 kit (Sigma-Aldrich).

For the measurement of triacylglycerol content, cells treated with seaweed extracts at $0.1 \mathrm{mg} / \mathrm{mL}$ for $24 \mathrm{~h}$, were washed thoroughly with PBS and incubated with hexane/isopropanol $(2: 1, \mathrm{v} / \mathrm{v}) 3$ times. Then, total volume was evaporated by vacuumed centrifugation and the pellet resuspended in $200 \mu \mathrm{L}$ Triton $\mathrm{X}-100$ in $1 \%$ distilled water. Finally, by means of sonication, triacylglycerols were disrupted and the content measured 233 using a commercial kit (Infinity Triglycerides reagent, Thermo Electron Corporation, 234 Rockford, IL, USA). In order to determine the protein amounts of the cells, these were lysed 235 in $0.3 \mathrm{~N} \mathrm{NaOH}, 0.1 \% \mathrm{SDS}$, and protein measured using the BCA reagent (Thermo Scientific, 236 Rockford, IL, USA). Triacylglycerol content were expressed as $\mathrm{mg} / \mathrm{mg}$ of protein and 237 converted into arbitrary units. 
All assays were performed at least in triplicate. Data represent the mean and standard

deviation of three independent experiments $(n=6$ for experiments in cell cultures and for the rest of experiments $n=3$ ). Data were subjected to one-way ANOVA by using Statgraphics version 16.1.17 software (Statistical Graphics Corp., Rockville, USA). Differences between samples were compared by using a Duncan's multiple-range test at $p<0.05$ probability level.

\section{Results and Discussion}

3.1. Liquid chromatography-tandem mass spectrometry (LC-MS/MS) characterization of the extracts

LC-MS profiles of all the seven algae extracts showed similar chromatographic elution of compounds with several compounds common among most of the samples (Figure 1). 249 Several compounds including monomeric sugars along with lipophilic constituents were 250 identified based on the predicted elemental composition following accurate mass 251 measurements of the deprotonated, i.e. $[\mathrm{M}-\mathrm{H}]^{-}$, ions (Table 1). The $[\mathrm{M}-\mathrm{H}]^{-}$ions for 252 monomeric sugars at $\mathrm{m} / z 181.0682\left(\mathrm{C}_{6} \mathrm{H}_{13} \mathrm{O}_{6}{ }^{-}\right)$for mannitol, $\mathrm{m} / z 165.0796\left(\mathrm{C}_{6} \mathrm{H}_{13} \mathrm{O}_{5}{ }^{-}\right)$for 253 fucitol, $m / z 193$ for glucuronic acid were observed in most of the samples. Ions at $\mathrm{m} / \mathrm{z} 325$ 254 corresponding to deprotonated molecular ions of a disaccharide fucose-hexose were detected 255 in C. crispus, H. elongata and U. pinnatifida (Table 1). As marine environment is a good 256 medium for the synthesis of sulphated secondary metabolites in algae and the presence of 257 sulphated oligosaccharides has been extensively described (Gonçalves, Ducatti, Duarte, \& 258 Noseda, 2002; Gonçalves et al., 2005), a set of sulphated sugars with $\mathrm{m} / \mathrm{z} 231$ (xylitol 259 sulphate), $m / z 214$ (dehydrated xylitol sulphate), $m / z 261$ (mannitol sulphate), $m / z 265$ 260 (sodiated fucose sulphate) and $\mathrm{m} / \mathrm{z} 259$ (hexose sulphate) were also detected. 
263

these non-polar molecules were reached through accurate measurements and tandem mass

spectrometry (MS/MS) fragmentation patterns aided by existing literature (Sajiki \& Kakimi, 1998; Santos et al., 2015). Deprotonated ions for fatty acids were observed at $\mathrm{m} / \mathrm{z} 187$ (nonanedioic acid), $m / z 215.1681\left(\mathrm{C}_{12} \mathrm{H}_{23} \mathrm{O}_{3}{ }^{-}\right.$), (hydroxydodecanoic acid), $\mathrm{m} / \mathrm{z} 327$ (oxodihydroxyoctadecenoic acid), $m / z 297.2412\left(\mathrm{C}_{18} \mathrm{H}_{33} \mathrm{O}_{3}{ }^{-}\right)$(epoxyoctadecanoic acid) and $\mathrm{m} / \mathrm{z}$ 329 (trihydroxyoctadecenoic acid). Ions at $\mathrm{m} / \mathrm{z} 325$ (dinor-11-PG $\mathrm{PG}_{\mathrm{F}} 2 \alpha$ ), $\mathrm{m} / \mathrm{z} 351.2184$ $\left(\mathrm{C}_{20} \mathrm{H}_{31} \mathrm{O}_{5}{ }^{-}\right)\left(\mathrm{PG}_{\mathrm{E} 2 / \mathrm{H} 2}\right), \mathrm{m} / z 353\left(\mathrm{PG}_{\mathrm{F} 2 \alpha}\right), 367.2094\left(\mathrm{C}_{20} \mathrm{H}_{31} \mathrm{O}_{6}{ }^{-}\right)$(hydroxy $\left.\mathrm{PG}_{\mathrm{F} 3 \alpha}\right), 369.2239$ $\left(\mathrm{C}_{20} \mathrm{H}_{33} \mathrm{O}_{6}{ }^{-}\right)$(hydroxy $\mathrm{PG}_{\mathrm{F} 2 \alpha}$ ) corresponding to a series of prostaglandins were detected in the extracts and have been reported previously in red algae (Sajiki \& Kakimi, 1998). Ions at $\mathrm{m} / \mathrm{z}$ $653.3768\left(\mathrm{C}_{31} \mathrm{H}_{57} \mathrm{O}_{14}{ }^{-}\right)$were tentatively identified as digalactosyl glyceryl palmitate and were 273 present in all the samples except $H$. elongata and U. pinnatifida (Table 1). Phosphatidic acid 274 (34:1) corresponding to ions at $\mathrm{m} / \mathrm{z} 673$, identified through accurate mass measurements and 275 fragmentation pattern as reported by Kind et al. (Kind, Liu, Lee, Defelice, Meissen, \& Fiehn, 2013), was detected only in $H$. elongata while Lysophosphatidylcholine $\left(\mathrm{C} 16: 0-\mathrm{CH}_{3}\right)$, found in macroalgae (Yao et al., 2015), with $m / z 480.3080\left(\mathrm{C}_{23} \mathrm{H}_{47} \mathrm{O}_{7} \mathrm{NP}^{-}\right)$ions was present in L. ochroleuca and P. palmata.

Several antioxidants that have not been detected by the LC-MS/MS analysis performed in this study are likely to be present in the obtained extracts. In fact, Kellogg et al. (2015) explored the active subfractions purified from methanolic extracts obtained from six different seaweed species collected in Alaska to determine the phytochemical constituents. In that study, the authors confirmed the presence of fucophloroethol and phlorotannin oligomers. Further, other compounds such us monoglycosyldiacylglycerol (MGDG), featuring two eicosatetraenoic acid residues were also detected in the extracts (Kellogg et al., 2015).

\subsection{Total phenolic content of seaweed extracts}


Total phenols (TP) were determined in the methanolic extracts since polyphenols are common seaweed compounds (Duan, Zhang, Li, \& Wang, 2006; Kuda et al., 2007; Lim, Cheung, Ooi, \& Ang, 2002) and are associated with various biological properties. TP values ranged from 0.54 to $24.04 \mathrm{GAE} / \mathrm{g}$ among all the seaweed extracts (Figure 2A). H. elongata showed significant $(\mathrm{p} \leq 0.05)$ higher TP values compared to the other six seaweed species studied. The lowest TP values were observed in U. pinnatifida followed by Ulva spp, L. ochroleuca, C. crispus, P. palmata and Phorphyra spp. The values were lower than those reported by other authors (Rajauria, Jaiswal, Abu-Gannam, \& Gupta, 2013), probably due to the different type of extraction and concentration of methanol used during the extraction procedure.

\subsection{Antioxidant properties of seaweeds and seaweed extracts}

DPPH. Seaweed extracts were evaluated in order to measure their DPPH-radical scavenging capacity. The highest DPPH reduction (87\%) was obtained with $H$. elongata extract (Figure 2B). A significant positive correlation was observed between TP and DPPH $(\mathrm{r}=0.9523 ; p<0.001)$, suggesting that polyphenols may be the main components involved in the antiradical properties of the extract (Rajauria et al., 2013). Nevertheless, in accordance with the results reported by other authors, it is important to mention that the polysaccharides and covalently linked phenols can also be involved in this activity (Wang et al., 2016).

TEAC. Methanolic extracts displayed antioxidant activity as they were able to scavenge the $\mathrm{ABTS}^{-+}$radical cation, showing significant differences among seaweed species (Figure 2C). The extract from H. elongata showed again the highest activity $(107.215 \mu \mathrm{mol}$ $\mathrm{TE} / \mathrm{g}$ ), meanwhile the rest of the extracts resulted in lower scavenging activities (3.48 to 15.85 $\mu \mathrm{mol} \mathrm{TE} / \mathrm{g})$. 
ORAC. This method, which determines peroxyl radical scavenging activity, showed

311

312

313

8

9

the same trend observed with other antioxidant methods; H. elongata had significantly $(p \leq 0.05)$ highest antioxidant activity $(61.85 \mu \mathrm{mol} \mathrm{TE} / \mathrm{g})$ than the rest of seaweeds evaluated (3.77 to $12.34 \mu \mathrm{mol} \mathrm{TE} / \mathrm{g}$ ) (Figure 2D).

314 Results showed a significant $(p \leq 0.05)$ correlation between phenol content and antioxidant 315 activity (data not shown) although probably other compounds such as sulphated 316 polysaccharides (fucans) and minor amounts of other sugars (including galactose, xylose, 317 glucose, among others) in their composition may also be involved in these properties (Lim, 318 Cheung, Ooi, \& Ang, 2002) (Table 1).

FRAP. Reducing power of the extracts was analyzed, since it is frequently related to the degree of hydroxylation and extent of conjugation in polyphenols. H. elongata showed higher activity $(1.44 \pm 0.88 \mu \mathrm{mol} \mathrm{Fe} / \mathrm{g})$ than the other seaweed extracts, where values ranged from 0.06 to $0.14 \mu \mathrm{mol} \mathrm{Fe} / \mathrm{g}$. (Figure $2 \mathrm{E})$. The lowest values appeared in U. pinnatifida $(0.06$ $\mu \mathrm{mol} \mathrm{Fe} / \mathrm{g}$ ) and the other seaweed extracts showed FRAP values close to H. elongata.

The antioxidant activity measured by all those methods could be attributed mainly to the presence of phenolic compounds in seaweeds extracts (Vo Dinh, Saravana, Woo, \& Chun, 2018). However, some sulfated sugars identified in the seaweeds extracts obtained in the present work (xylitol sulphate, mannitol sulphate, anhydrous xylitol sulphate, hexose sulphate and sodiated fucose sulphate) that may be also contributing to the antioxidant activity of these extracts. This hypothesis is supported by different studies that have found antioxidant activity of seaweed sulfated polysaccharides by different in vitro methods such as ABTS radical scavenging (Gómez-Ordóñez, Jiménez-Escrig, \& Rupérez, 2014), DPPH radical scavenging (Seedevi, Moovendhan, Viramani, \& Shanmugam, 2017), FRAP (Xie, Wang, Shen, Nie, Gong, Li, et al., 2016), lipid peroxide inhibition (Ben Gara, Ben Abdallah Kolsi, Chaaben, 
Hammami, Kammoun, Paolo Patti, et al., 2017), and superoxide and hydroxyl radical scavenging assays (Abu, Jiang, Ueno, Okimura, Yamaguchi, \& Oda, 2013; Deng, Xu, Fu, Chen, \& Xu, 2015), among others.

Antioxidant capacity was also measured through direct methods (DPPH and TEAC) 338 (Figure 3A and 3B). Results showed, as it occurred in extract-based methods, higher antioxidant activity of $H$. elongata as compared to the other seaweeds studied. However, DPPH reduction assay revealed relatively high antiradical effect of $U$. pinnatifida, $L$. ochroleuca and P. palmata, higher than 50\% reduction, which could explain that other nonsoluble compounds may also contribute on their total antioxidant activity.

\subsection{Antihypertensive properties of seaweed}

Inhibition of ACE-I is a well-established approach in the treatment of hypertension, and because of that, many authors have screened the potential of seaweeds in inhibiting this enzyme. Cha et al. (2006) screened the in vitro ACE-I inhibitory activity of methanol and aqueous extracts from twenty-six red Korean algae, obtained at $20^{\circ} \mathrm{C}$ or at $70{ }^{\circ} \mathrm{C}$. The authors found several potential extracts, with $\mathrm{IC}_{50}$ values for ACE-I in the range of 12.21-124.69 $\mu \mathrm{g} / \mathrm{mL}$. In our study, among the tested seaweeds, only $H$. elongata showed ACE inhibitory potential $\left(\mathrm{IC}_{50}=65 \mu \mathrm{g} / \mathrm{mL}\right)$, with and active concentration in the range previously reported by Cha et al (2006). Furthermore, the range of the $\mathrm{IC}_{50}$ observed for $H$. elongata is only ten-fold higher (lower activity) than those found in works applying proteolytic enzymatic digestions for screening ACE-I-inhibitory bioactive peptides (Cardoso et al., 2015; Suetsuna, Maekawa, \& Chen, 2004).

\subsection{Anti-inflammatory activity of seaweed extracts}

In diet-induced obesity, adipose tissue is in a chronic low-grade state of inflammation predisposing the development of MetS. This event is driven by the infiltration of macrophages 
into adipose tissue, which, together with adipocytes, perpetuate a cycle of macrophage 359 recruitment and secretion of free fatty acids and deleterious cytokines/chemokines that 360 predispose to development of MetS (Dandona et al., 2005). Newly released inflammatory 361 cytokines drives the inflammatory responses to upregulate pro-inflammatory genes expression 362 such as inducible nitric oxide synthase (iNOS) and cyclooxygenase-2 (COX2) and contribute 363 to the progression of systemic inflammation (Dandona et al., 2005). The former is involved in 364 NO synthesis and the latter represent a key enzyme in the synthesis of lipid inflammatory 365 mediators that include prostaglandins. One potential strategy to reduce obesity-induced 366 inflammation is to inhibit the activity and expression of these proinflammatory enzymes ( $\mathrm{Gu}$ 367 et al., 2014). Therefore, we evaluated the anti-inflammatory potential of seaweed extracts in a 368 model of LPS-induced RAW264.7 macrophages in culture. Methanolic extracts from the 369 seven seaweed species were evaluated for their cytotoxic effect on RAW 264.7 macrophages. 370 Results showed that the seaweed extracts did not significantly $(p<0.05)$ affect cell viability $(\geq$ $37190 \%$ of the control) indicating that the tested concentration did not damage cell integrity 372 (Figure 4A). This non-toxic extract dose was assayed for their inhibitory potential against 373 three common pro-inflammatory markers $\mathrm{NO}, \mathrm{TNF}-\alpha$ and $\mathrm{PGD}_{2}$. Previous studies have 374 demonstrated that $\mathrm{PGD}_{2}$ is the most abundant cyclooxygenase 2 (COX-2) product in LPS375 stimulated RAW264.7 macrophages (Buczynski et al., 2007). NO and $\mathrm{PGD}_{2}$ were determined 376 in LPS-stimulated RAW264.7 macrophages as a biomarker of iNOS and COX-2 activity.

377 To investigate if seaweed extracts exert anti-inflammatory properties, RAW 264.7 cells were 378 pre-treated with $500 \mu \mathrm{g} / \mathrm{mL}$ algae extracts for $24 \mathrm{~h}$ and subsequently stimulated with 10 $379 \mu \mathrm{g} / \mathrm{mL}$ LPS for $24 \mathrm{~h}$. Production of NO, $\mathrm{PGD}_{2}$, and TNF- $\alpha$ was measured in the culture 380 medium. When LPS was administered to non-pretreated macrophages the NO production, and $381 \mathrm{PGD}_{2}$ and TNF- $\alpha$ secretion was increased significantly $(p<0.05)$ from the basal level after 24 $\mathrm{h}$ incubation (Figures 4B-4D), indicating the successful activation of cells by LPS stimulation. 
The results showed that most of the extracts evaluated were able to reduce significantly $(p<0.05)$ the NO production in LPS-activated macrophages $(>50 \%$ of inhibition) (Figure 4B). This reduction was notably higher in cells treated with $U$. pinnatifida and H. elongata extracts ( $\sim 92.5 \%$ and $\sim 74.8 \%$ of inhibition, respectively). On the other hand, the Porphyra spp., $U$. pinnatifida, C. crispus, and L. ochroleuca extracts, at a dose of $500 \mu \mathrm{g} / \mathrm{mL}$, exhibited a significant reduction $(p<0.05)$ in the level of LPS-induced $\mathrm{PGD}_{2}$ and TNF- $\alpha$ (Figure $4 \mathrm{C}$ and 4D). Noteworthy, cell treatment in presence of $U$. pinnatifida extract was extremely effective in the inhibition of pro-inflammatory $\mathrm{PGD}_{2}$ and $\mathrm{TNF}-\alpha(\sim 96.5 \%$ and $\sim 77.5 \%$, respectively). 391 However, even though $H$. elongata and $P$. palmata extracts were significantly $(p<0.05)$ 392 effective reducing the LPS-induced $\mathrm{PGD}_{2}$ secretion, they did not evoke a significant $(p>0.05)$ 393 reduction on the TNF- $\alpha$ levels (Figure 4D). Differences in the anti-inflammatory activity of 394 seaweed extracts could be due to variations in composition of bioactive compounds.

Our results are consistent with previous studies showing the anti-inflammatory effects of seaweed extracts from brown, green and red seaweed species (Joung et al., 2017; Kellogg et al., 2015). All species (Sargassum serratifolium, Dictiopteris divaricate, Dictyopteris prolifera, Prionitis cornea, Grateloupia lanceolate, Grateloupia filicina, Fucus distichus, Alaria marginate, Saccharina groenlandica, and Saccharina latissimi, Ecklonia stolonifera) strongly inhibited NO production, decreased secretion of $\mathrm{PGE}_{2}$ and, TNF- $\alpha$ and interleukin (IL)-6 and protein expression of inducible NO synthase and COX-2. Fatty acids and lipid derivatives from different marine algae species have shown anti-inflammatory potential in LPS-activated RAW 264.7 macrophages (Dang et al., 2008; Lee et al., 2009). The antiinflammatory potential of $H$. elongata and $U$. pinnatifida could be supported by the presence of dihydroxy-oxo-octadecenoic, trihydroxyoctadecenoic and nonanodieic acids found in methanolic extracts. The structure-activity relationship of oxygenated fatty acids have revealed that the presence of $\alpha, \beta$-unsaturated carbonyl moiety significantly enhances the 
anti-inflammatory activity of LPS induced RAW cells along with some other minor structural features such as; chain length, terminal functional group and position of enone groups (Dang et al., 2008).

Other bioactive compounds not identified herein could have been contributed to the overall anti-inflammatory activity of seaweed extracts. For instance, seaweed phlorotannin oligomers ranging from 9 to 20 have been shown with the potential to inhibit inflammatory markers, including prostaglandin synthesis, through a potential mechanism of down regulation of the expression of Toll-like receptors such as TLR4 and TLR9 (Kellogg et al., 2015). In particular, phloroglucinol, eckol, dieckol, 7-phloroeckol, phlorofucofuroeckol A and dioxinodehydroeckol from brown seaweed species has been reported as pronounced inhibitors of pro-inflammatory enzymes and cytokines in LPS-stimulated macrophages (Jung et al., 2013). More recently, sargahydroquinoic acid, argachromenol, and sagaquinoic acid were identified as the main anti-inflammatory compounds in the brown algae Sargassum serratifolium (Joung et al., 2017). Sulfated polysaccharides such as fucoidans are also an interesting group of anti-inflammatory compounds abundant in brown seaweeds. There are at

least two distinct forms of fucoidan: F-fucoidan, which is $>95 \%$ composed of sulfated esters of fucose, and U-fucoidan, which is approximately $20 \%$ glucuronic acid. Current findings confirm that isolated fucoidans from brown seaweeds species inhibit NO production and expression of PGs through the subsequent downregulation of iNOS and COX-2 expression in 430 however, there is no evidence so far showing the anti-inflammatory effect of these small 431 compounds.

\section{$432 \quad 3.6$ Adipocyte viability and triacylglyceride-lowering activity}


P. palmata seaweed extract showed cytotoxic effects when added to the mature

adipocytes in the three tested doses $(0.05,0.1$ and $0.5 \mathrm{mg} / \mathrm{mL})$ (Figure $5 \mathrm{~A})$. Regarding all the other extracts, no cytotoxic effects were observed under the aforementioned extract doses. Other authors did not find cytotoxic effects of extracts from seaweeds, other than those used in this study, up to a $48 \mathrm{~h}$ incubation period in 3T3-L1 preadipocytes at a dose of $0.1 \mathrm{mg} / \mathrm{mL}$ (Ko et al., 2013). Further, in a study performed in mature adipocytes incubated for $48 \mathrm{~h}$ with fucoxanthin, a major marine carotenoid isolated from brown seaweeds such as U. pinnatifida, at doses up to $20 \mu \mathrm{M}$, no cytotoxic effect was found (Kang et al., 2011). However, Kang et al. (2016b), in their extensive study performed with a great number of brown, green and red 442 seaweeds obtained from Jeju Island (Korea), reported a cytotoxic effect for an ethanolic 443 extract obtained from some seaweeds, including $U$. pinnatifida, after incubating preadipocytes 444 for $48 \mathrm{~h}$ with $0.1 \mathrm{mg} / \mathrm{mL}$ of the extract.

Taking into account the cell viability assay results, the $0.1 \mathrm{mg} / \mathrm{mL}$ extract dose was selected to analyze the effects of the studied seaweeds regarding their triacylglyceride lowering activity. The extracts obtained from P. palmata, Ulva spp., U. pinnafitida and $H$. elongata induced significant reductions $(42.96 \%, 49.96 \%, 36.35 \%$ and $52.0 \%$ respectively) in triacylglycerol content in mature 3T3-L1 adipocytes after $24 \mathrm{~h}$ incubation (Figure 5B).

Obesity and overweight processes are determined not only by adipocyte hyperplasia (increasing the number of adipocytes) but also by adipose tissues grow by hypertrophy (increasing the size of their adipocytes). It seems that a "critical" adipocyte size exists, triggering the recruitment of preadipocytes that eventually differentiated into mature adipocytes (Faust, Johnson, Stern, \& Hirsch, 1978). In this line, some extracts obtained from different types of seaweeds, including one from $U$. pinnatifida, have also shown triglyceride reducing effect in maturing adipocytes (Kang et al., 2016b). These authors, in a study performed in 3T3-L1 preadipocytes with an extract from Gelidium amansii devoted to explore 
458 the mechanisms underlying the inhibition of intracellular lipid accumulation, demonstrated 459 that an ethanolic extract at a concentration of $100 \mu \mathrm{g} / \mathrm{mL}$ decreased protein expression levels 460 of some adipogenic-specific proteins (PPAP $\gamma, \mathrm{C} / \mathrm{EBP} \alpha$, and SREBP-1), compared to the non461 treated cells (Kang et al., 2016a). Furthermore, fucoxanthin, marine carotenoid found in 462 edible brown seaweeds such as $U$. pinnatifida and Laminaria japonica, reduced the 463 expression of PPAR $\gamma, \mathrm{C} / \mathrm{EBP} \alpha$, and SREBP1c during the intermediate and late stages of 464 adipocyte differentiation (Kang, et al., 2011). Similar effects were found by Yim et al. (2011) 465 in a study devoted to investigate the effects of fucoxanthin and its metabolites, fucoxanthinol 466 and amarouciaxanthin A, on 3T3-L1 preadipocyte differentiation. These authors concluded 467 that amarouciaxanthin A reduces 3T3-L1 adipocyte differentiation through the down468 regulation of PPAR $\gamma$ and $\mathrm{C} / \mathrm{EBP} \alpha$ mRNA expression (Yim, et al., 2011). Some of these 469 compounds are likely to be present in our extracts since Kellogg et al (2015) also using an aqueous methanolic solution detected fucophloroethol and phlorotannin oligomers in a subfraction of the obtained extracts, and show them as responsible for the reduction in triacylglyceride accumulation observed in adipocytes (Kellogg et al., 2015).

To the best of our knowledge, this is the first study conducted with mature adipocytes aimed to analyze the viability and triacylglyceride accumulation after seaweed extract treatment. Considering that systemic metabolic dysfunction - unhealthy obesity- is primarily associated with mature adipocyte hypertrophy (Lessard et al., 2014), extracts from Ulva spp., P. palmata, $U$. pinnatifida and $H$. elongata could be considered as potential tool in reducing obesity.

\section{Conclusions}

This is the first study that evaluated the multifunctional potential of mostly consumed seaweeds with the objective to identify a species displaying an array of relevant bioactivities 
to attenuate the cardiometabolic risk factors of MetS. Among seaweeds, H. elongata showed 483 the better potential to be used as raw material in the development of new functional foods for 484 management of MetS. Methanolic extracts of this seaweed species showed the highest 485 phenolic content, antioxidant activity and angiotensin converting enzyme I inhibitory activity 486 in vitro. In addition, $H$. elongata effectively reduced LPS-induced inflammation in RAW 487264.7 macrophages and triglyceride accumulation in 3T3-L1 mature adipocytes. 488 Phytochemical investigations by LC-MS indicated the presence of monomeric sugars/sulfated 489 sugars and lipids in the bioactive extracts.

\section{Acknowledgements}

This study has been supported by the National Institute for Agricultural and Food Research and Technology of Spain (INIA: RTA2014-0037-C02).

\section{Conflict of interest}

The authors declare that there are no conflicts of interest.

\section{References}

Abu, R., Jiang, Z., Ueno, M., Okimura, T., Yamaguchi, K., \& Oda, T. (2013). In vitro antioxidant activities of sulfated polysaccharide ascophyllan isolated from Ascophyllum nodosum. International Journal of Biological Macromolecules, 59, $305-$ 312.

Alberti, K. G. M. M., Eckel, R. H., Grundy, S. M., Zimmet, P. Z., Cleeman, J. I., Donato, K. A., Fruchart, J. C., James, W. P. T., Loria, C. M., \& Smith, S. C. (2009). Harmonizing the metabolic syndrome: A joint interim statement of the international diabetes federation task force on epidemiology and prevention; National heart, lung, and blood institute; American heart association; World heart federation; International 

1

atherosclerosis society; And international association for the study of obesity. Circulation, 120, 1640-1645.

Brand-Williams, W., Cuvelier, M. E., \& Berset, C. (1995). Use of a free radical method to evaluate antioxidant activity. LWT - Food Science and Technology, 28, 25-30.

Buczynski, M. W., Stephens, D. L., Bowers-Gentry, R. C., Grkovich, A., Deems, R. A., Dennis, E. A. (2007). TLR-4 and sustained calcium agonists synergically produce eicosanoids independent of protein synthesis in RAW264.7 cells. Journal of Biological Chemistry, 282, 22834-22847.

Cardoso, S. M., Pereira, O. R., Seca, A. M. L., Pinto, D. C. G. A., \& Silva, A. M. S. (2015). Seaweeds as preventive agents for cardiovascular diseases: From nutrients to functional foods. Marine Drugs, 13, 6838-6865.

Cox, S., Abu-Ghannam, N., \& Gupta, S. (2010). An assessment of the antioxidant and antimicrobial activity of six species of edible Irish seaweeds. International Food Research Journal, 17, 205-220.

Cha, S.-H. L., K.-W.; Jeon, Y.-J. (2006). Screening of extracts from red algae in Jeju for potentials marine angiotensin-I converting enzyme (ACE) inhibitory activity. Algae, $21,343-348$.

Charoensiddhi, S., Conlon, M. A., Methacanon, P., Franco, C. M. M., Su, P., \& Zhang, W. (2017). Gut health benefits of brown seaweed Ecklonia radiata and its polysaccharides demonstrated in vivo in a rat model. Journal of Functional Foods, 37(Supplement C), 676-684.

Dandona, P., Aljada, A., Chaudhuri, A., Mohanty, P., \& Garg, R. (2005). Metabolic syndrome: A comprehensive perspective based on interactions between obesity, diabetes, and inflammation. Circulation, 111, 1448-1454. 
530 Dang, H.T., Lee, H.J., Yoo, E.S., Shinde, P.B., Lee, Y.M., Hong, J., Kim, D.K., Jung, J.H.

(2008). Anti-inflammatory constituents of the red alga Gracilaria verrucosa and their synthetic analogues. Journal of Natural Products, 71, 232-240.

Deng, C., Xu, J., Fu, H., Chen, J., \& Xu, X. (2015). Characterization, antioxidant and cytotoxic activity of sulfated derivatives of a water-insoluble polysaccharides from Dictyophora indusiata. Molecular Medicine Reports, 11, 2991-2998.

Delaney, A., Frangoudes, K., \& Li, S.A. (2016). Society and Seaweed: Understanding the Past and Present. In: Seaweed in Health and Disease Prevention. Elsevier Academic Pess, $17-40$.

Duan, X. J., Zhang, W. W., Li, X. M., \& Wang, B. G. (2006). Evaluation of antioxidant property of extract and fractions obtained from a red alga, Polysiphonia urceolata. Food Chemistry, 95, 37-43.

Faust, I. M., Johnson, P. R., Stern, J. S., \& Hirsch, J. (1978). Diet-induced adipocyte number increase in adult rats: a new model of obesity. The American journal of physiology, 235, E279-286.

Gómez-Ordóñez, E., Jiménez-Escrig, A., \& Rupérez, P. (2014). Bioactivity of sulfated polysaccharides from the edible red seaweed Mastocarpus stellatus. Bioactive Carbohydrates and Dietary Fibre, 3, 29-40.

Gonçalves, A. G., Ducatti, D. R. B., Duarte, M. E. R., \& Noseda, M. D. (2002). Sulfated and pyruvylated disaccharide alditols obtained from a red seaweed galactan: ESIMS and NMR approaches. Carbohydrate Research, 337, 2443-2453.

Gonçalves, A. G., Ducatti, D. R. B., Paranha, R. G., Eugênia, M., Duarte, R., \& Noseda, M. D. (2005). Positional isomers of sulfated oligosaccharides obtained from agarans and carrageenans: Preparation and capillary electrophoresis separation. Carbohydrate Research, 340, 2123-2134. 
5 1

555 González-Montoya, M., Hernández-Ledesma, B., Silván, J. M., Mora-Escobedo, R., \& 556 Martínez-Villaluenga, C. (2018). Peptides derived from in vitro gastrointestinal digestion of germinated soybean proteins inhibit human colon cancer cells proliferation and inflammation. Food Chemistry, 242(Supplement C), 75-82.

Grasa-López, A., Miliar-García, Á., Quevedo-Corona, L., Paniagua-Castro, N., EscalonaCardoso, G., Reyes-Maldonado, E., \& Jaramillo-Flores, M. E. (2016). Undaria pinnatifida and fucoxanthin ameliorate lipogenesis and markers of both inflammation and cardiovascular dysfunction in an animal model of diet-induced obesity. Marine Drugs, 14(8).

Grosso, G., Marventano, S., Yang, J., Micek, A., Pajak, A., Scalfi, L., Galvano, F., \& Kales, S. N. (2017). A comprehensive meta-analysis on evidence of Mediterranean diet and cardiovascular disease: Are individual components equal? Critical Reviews in Food Science and Nutrition, 57, 3218-3232.

Grundy, S. M. (2016). Metabolic syndrome update. Trends in Cardiovascular Medicine, 26, 364-373.

Gu, Y., Yu, S., Park, J., Harvatine, K., \& Lambert, J. (2014). Dietary cocoa reduces metabolic endotoxemia and adipose tissue inflammation in high-fat fed mice. The Journal of Nutritional Biochemistry, 25, 439-445.

Gupta, S., \& Abu-Ghannam, N. (2011). Bioactive potential and possible health effects of edible brown seaweeds. Trends in Food Science and Technology, 22, 315-326.

Han, Y. R., Ali, M. Y., Woo, M. H., Jung, H. A., \& Choi, J. S. (2015). Anti-Diabetic and Anti-Inflammatory Potential of the Edible Brown Alga Hizikia Fusiformis. Journal of Food Biochemistry, 39, 417-428. 
578 Hassan, M. R. (2009). Use of algae and aquatic macrophytes as feed in small-scale aquaculture: A review. Technical Paper 531, FAO Fisheries and Aquaculture Department, Rome, Italy.

Hyseni, L., Atkinson, M., Bromley, H., Orton, L., Lloyd-Williams, F., McGill, R., \& Capewell, S. (2017). The effects of policy actions to improve population dietary patterns and prevent diet-related non-communicable diseases: Scoping review. European Journal of Clinical Nutrition, 71, 694-711.

Jeong, J-W., Hwang, S. J., Han, M. H., Lee, D-S., Yoo, J. S., Choi, I-W., Cha, H-J., Kim, S., Kim, H-S., Kim, G-Y., Jeon, Y-J., Lee, H-J., Park, H. T., Yoo, Y. H., Choi, Y. H. (2017). Fucoidan inhibits lipopolysaccharide-induced inflammatory responses in RAW 264.7 macrophages and zebrafish larvae. Molecular \& Cellular Toxicology, 13, 405-417.

Joung, E. J., Gwon, W. G., Shin, T., Jung, B. M., Choi, J. S., \& Kim, H. R. (2017). Antiinflammatory action of the ethanolic extract from Sargassum serratifolium on lipopolysaccharide-stimulated mouse peritoneal macrophages and identification of active components. Journal of Applied Phycology, 29, 563-573.

Jung, H.A., Jin, S.E., Ahn, B.R., Lee, C.M., Choi, J.S. (2013). Anti-inflammatory activity of edible brown alga Eisenia bicyclis and its constituents fucosterol and phlorotannins in LPS stimulated RAW264.7 macrophages. Food and Chemical Toxicology, 59, 199206.

Kang, M. C., Kang, N., Kim, S. Y., Lima, I. S., Ko, S. C., Kim, Y. T., Kim, Y. B., Jeung, H. D., Choi, K. S., \& Jeon, Y. J. (2016a). Popular edible seaweed, Gelidium amansii prevents against diet-induced obesity. Food and Chemical Toxicology, 90, 181-187. 
Kang, M. C., Kang, N., Ko, S. C., Kim, Y. B., \& Jeon, Y. J. (2016b). Anti-obesity effects of seaweeds of Jeju Island on the differentiation of 3T3-L1 preadipocytes and obese mice fed a high-fat diet. Food and Chemical Toxicology, 90, 36-44.

Kang, M. C., Wijesinghe, W. A. J. P., Lee, S. H., Kang, S. M., Ko, S. C., Yang, X., Kang, N., Jeon, B. T., Kim, J., Lee, D. H., \& Jeon, Y. J. (2013). Dieckol isolated from brown seaweed Ecklonia cava attenuates type II diabetes in $\mathrm{db} / \mathrm{db}$ mouse model. Food and Chemical Toxicology, 53, 294-298.

Kang, S. I., Ko, H. C., Shin, H. S., Kim, H. M., Hong, Y. S., Lee, N. H., \& Kim, S. J. (2011). Fucoxanthin exerts differing effects on 3T3-L1 cells according to differentiation stage and inhibits glucose uptake in mature adipocytes. Biochemical and Biophysical Research Communications, 409, 769-774.

Kellogg, J., Esposito, D., Grace, M. H., Komarnytsky, S., \& Lila, M. A. (2015). Alaskan seaweeds lower inflammation in RAW 264.7 macrophages and decrease lipid accumulation in 3T3-L1 adipocytes. Journal of Functional Foods, 15, 396-407.

Kind, T., Liu, K. H., Lee, D. Y., Defelice, B., Meissen, J. K., \& Fiehn, O. (2013). LipidBlast in silico tandem mass spectrometry database for lipid identification. Nature Methods, 10(8), 755-758.

Ko, S. C., Lee, M., Lee, J. H., Lee, S. H., Lim, Y., \& Jeon, Y. J. (2013). Dieckol, a phlorotannin isolated from a brown seaweed, Ecklonia cava, inhibits adipogenesis through AMP-activated protein kinase (AMPK) activation in 3T3-L1 preadipocytes. Environmental Toxicology and Pharmacology, 36, 1253-1260.

Kuda, T., Kunii, T., Goto, H., Suzuki, T., \& Yano, T. (2007). Varieties of antioxidant and antibacterial properties of Ecklonia stolonifera and Ecklonia kurome products harvested and processed in the Noto peninsula, Japan. Food Chemistry, 103, 900-905. 
Lee, H.J., Dang, H.T., Kang, G.J., Yang, E.J., Park, S.S., Yoon, W.J., Jung, J.H., Kang, H.K., Yoo, E.S. (2009). Two enone fatty acids isolated from Gracilaria verrucosa suppress the production of inflammatory mediators by down-regulating NF-kappaB and STAT1 activity in lipopolysaccharide-stimulated RAW264.7 cells. Archives of Pharmaceutical Research, 32, 453-462.

Lessard, J., Laforest, S., Pelletier, M., Leboeuf, M., Blackburn, L., \& Tchernof, A. (2014). Low abdominal subcutaneous preadipocyte adipogenesis is associated with visceral obesity, visceral adipocyte hypertrophy, and a dysmetabolic state. Adipocyte, 3, 197205.

Levine, I. (2016). Algae: a way of life and health. In: Seaweed in Health and Disease Prevention. Elsevier Academic Pess, 1 - 5.

Lim, S. N., Cheung, P. C. K., Ooi, V. E. C., \& Ang, P. O. (2002). Evaluation of antioxidative activity of extracts from a brown seaweed, Sargassum siliquastrum. Journal of Agricultural and Food Chemistry, 50, 3862-3866.

Murray, M., Dordevic, A. L., Ryan, L., \& Bonham, M. P. (2017). An emerging trend in functional foods for the prevention of cardiovascular disease and diabetes: Marine algal polyphenols. Critical Reviews in Food Science and Nutrition, 1-17.

National Cholesterol Education Program (NCEP): Expert Panel on Detection and Treatment of High Boold Cholesterol in Adults (2002). Third Report of the National Chohlesterol Education Program (NCEP) Expert Panel on Detection, Evaluation, and Treatment of High Blood Cholesterol In Adults (Adult Treatment Pnel III) final report. Circulation, 106, 3143-3421.

Okada, T., Mizuno, Y., Sibayama, S., Hosokawa, M., \& Miyashita, K. (2011). Antiobesity effects of Undaria lipid capsules prepared with Scallop phospholipids. Journal of Food Science, 76, H2-H6. 
Ou, B., Hampsch-Woodill, M., \& Prior, R. L. (2001). Development and validation of an improved oxygen radical absorbance capacity assay using fluorescein as the fluorescent probe. Journal of Agricultural and Food Chemistry, 49, 4619-4626.

Pereira, J. A., Oliveira, I., Sousa, A., Ferreira, I. C. F. R., Bento, A., \& Estevinho, L. (2008). Bioactive properties and chemical composition of six walnut (Juglans regia L.) cultivars. Food and Chemical Toxicology, 46, 2103-2111.

Rajauria, G., Jaiswal, A. K., Abu-Gannam, N., \& Gupta, S. (2013). Antimicrobial, antioxidant and free radical-scavenging capacity of brown seaweed Himanthalia elongata from western coast of Ireland. Journal of Food Biochemistry, 37, 322-335.

Rioux, L-E., Beaulieu, L., \& Turgeon, S. L. (2018). Seaweeds: A traditional ingredients for new gastronomic sensation. Food Hydrocolloids, 68, 255-265.

Sajiki, J., \& Kakimi, H. (1998). Identification of eicosanoids in the red algae, Gracilaria asiatica, using high-performance liquid chromatography and electrospray ionization mass spectrometry. Journal of Chromatography A, 795, 227-237.

Santos, S. A. O., Vilela, C., Freire, C. S. R., Abreu, M. H., Rocha, S. M., \& Silvestre, A. J. D. (2015). Chlorophyta and Rhodophyta macroalgae: A source of health promoting phytochemicals. Food Chemistry, 183, 122-128.

Seedevi, P., Moovendhan, M., Viramani, S., \& Shanmugam, A. (2017). Bioactive potential and structural chracterization of sulfated polysaccharide from seaweed (Gracilaria corticata). Carbohydrate Polymers, 155, 516-524.

Serpen, A., Capuano, E., Fogliano, V., \& Gökmen, V. (2007). A new procedure to measure the antioxidant activity of insoluble food components. Journal of Agricultural and Food Chemistry, 55, 7676-7681. 
Shalaby, S. M., Zakora, M., \& Otte, J. (2006). Performance of two commonly used angiotensin-converting enzyme inhibition assays using FA-PGG and HHL as substrates. Journal of Dairy Research, 73, 178-186.

Slinkard, K. A. S., V. L. (1977). Total Phenol Analyses: Automation and comparison with manual methods. American Journal of Enology and Viticulture, 28, 49-55.

Smit, A. J. (2004). Medicinal and pharmaceutical uses of seaweed natural products: A review. Journal of Applied Phycology, 16, 245-262.

Suetsuna, K., Maekawa, K., \& Chen, J. R. (2004). Antihypertensive effects of Undaria pinnatifida (wakame) peptide on blood pressure in spontaneously hypertensive rats. Journal of Nutritional Biochemistry, 15, 267-272.

Tong, T., Ko, D. O., Kim, B. S., Ham, K. S., \& Kang, S. G. (2015). Beneficial effect of seaweed on high-fat diet-induced oxidative stress and insulin resistance in rats. Food Science and Biotechnology, 24, 2185-2191.

Vo Dinh, T., Saravana, P. S., Woo, H. C., \& Chun, B. S. (2018). Ionic liquid-assisted subcritical water enhances the extraction of phenolics from brown seaweed and its antioxidant activity. Separation and Purification Technology, 196, 287-299.

Wang, J., Hu, S., Nie, S., Yu, Q., \& Xie, M. (2016). Reviews on mechanisms of in vitro antioxidant activity of polysaccharides. Oxidative Medicine and Cellular Longevity, 2016, Article ID 5692852.

WHO. (2017). Noncommunicable diseases. Fact sheet number 355. http://www.who.int/mediacentre/factsheets/fs355/en/.

Xie, J.-H., Wang, Z.-J., Shen, M.-Y., Nie, S.-P., Gong, B., Li, H.-S., Zhao, Q., Li, W.-J., \& Xie, M.-Y. (2016). Sulfated modification, characterization and antioxidant activities of polysaccharide from Cyclocarya paliurus. Food Hydrocolloids, 53, 7-15. 
697 Yao, L., Gerde, J. A., Lee, S. L., Wang, T., \& Harrata, K. A. (2015). Microalgae lipid $698 \quad$ characterization. Journal of Agricultural and Food Chemistry, 63, 1773-1787.

699 Yim, M. J., Hosokawa, M., Mizushina, Y., Yoshida, H., Saito, Y., \& Miyashita, K. (2011).

700 Suppressive effects of amarouciaxanthin A on 3T3-L1 adipocyte differentiation 701 through down-regulation of PPAR $\gamma$ and $\mathrm{C} / \mathrm{EBP} \alpha$ mRNA expression. Journal of $702 \quad$ Agricultural and Food Chemistry, 59, 1646-1652. 
$704_{1}$ $705^{2}$ $706^{4}$ 7076

Figure 1. HPLC-MS/MS chromatograms for Porphyra purpurea (A), Undaria pinnatifida (B), Ulva spp. (C), Himanthalia elongata (D), Chondrus crispus (E), Laminaria ochroleuca (F) and Palmaria palmata (G).

Figure 2. Total phenolic compounds and antioxidant activities of Porphyra spp., Undaria pinnatifida, Ulva spp., Himanthalia elongata, Chondrus crispus, Laminaria ochroleuca and Palmaria palmata were assessed using the following methods: TP (A), DPPH (B), TEAC (C), ORAC (D) and FRAP (E). Data were expressed in $\mu \mathrm{mol}$ GAE (GAE)/g for TP, \% of reduction for DPPH, $\mu$ mol TE/g for TEAC, $\mu \mathrm{mol} \mathrm{TE} / \mathrm{g}$ for ORAC and $\mu \mathrm{mol} \mathrm{Fe} / \mathrm{g}$ for FRAP. Data are the mean \pm standard deviation of three replicates analyzed in duplicate. Different letters indicate statistical differences $(\mathrm{P}<0.05$, Duncan's test).

Figure 3. Direct measurement of total antioxidant capacity (QUENCHER) using DPPH and TEAC methods for Porphyra spp., Undaria pinnatifida, Ulva spp., Himanthalia elongata, Chondrus crispus, Laminaria ochroleuca and Palmaria palmata. Data were expressed as \% of reduction for DPPH and $\mu \mathrm{mol} \mathrm{TE} / \mathrm{g}$ for TEAC. Data are the mean \pm standard deviation of three replicates analyzed in duplicate. Different letters indicate statistical differences $(\mathrm{P}<0.05$, Duncan's test $)$.

Figure 4. Cytotoxic effect of seaweed extracts in RAW264.7 macrophages $(500 \mu \mathrm{g} / \mathrm{mL})(\mathbf{A})$. The results are expressed as percentage of control and are represented by mean \pm SD $(n=6)$. Effect of algae extracts $(500 \mu \mathrm{g} / \mathrm{mL})$ on NO production (B), PGD 2 (C), and TNF- $\alpha$ secretion (D) in LPS-stimulated RAW 264.7 macrophages. The results are expressed as percentage of control and are represented by mean $\pm \mathrm{SD}(\mathrm{n}=6)$. Significant decreased $(p<0.05) \mathrm{NO}, \mathrm{PGD}_{2}$, and TNF- $\alpha$ production is depicted with asterisk as compared to cells treated with LPS $(10 \mu \mathrm{g} / \mathrm{mL})$.

Figure 5.Cytotoxicity and triacylglyceride-lowering activity of seaweed extracts. 3T3-L1 mature adipocytes were treated for $24 \mathrm{~h}$ with $0.05,0.1$ or $0.5 \mathrm{mg} / \mathrm{mL}$ of different seaweed extracts, and their viability was evaluated by the neutral red assay (A). Triacylglycerol amounts in 3T3-L1 mature adipocytes incubated for $24 \mathrm{~h}$ with different seaweed extracts at a dose of $0.1 \mathrm{mg} / \mathrm{ml}(\mathrm{B})$. Data represent the mean $\pm \mathrm{SD}(\mathrm{n}=6)$. Asterisk indicate statistically significant differences $(P<0.05)$ compared with control condition. 
Table 1. Liquid chromatography-tandem mass spectrometry (LC-MS/MS). Identification of compounds based on $\mathrm{m} / \mathrm{z}$ and fragmentation pattern for Himanthalia elongata and Undaria pinnatifida

\begin{tabular}{ccccccc}
\hline ALGAE & $\boldsymbol{t}_{\mathbf{R}}$ & $\begin{array}{c}{[\mathbf{M}-\mathbf{H}]^{-}} \\
\boldsymbol{m} / \boldsymbol{z}\end{array}$ & $\begin{array}{c}\text { Mass Error } \\
(\mathbf{m D a})\end{array}$ & $\begin{array}{c}\text { Molecular } \\
\text { Formula }\end{array}$ & MS/MS fragment ions $(\boldsymbol{m} / \mathbf{z})$ & Tentative ID \\
\hline $\begin{array}{c}\text { Himanthalia } \\
\text { elongata }\end{array}$ & 1.4 & 325.1113 & -2.2 & $\mathrm{C}_{12} \mathrm{H}_{21} \mathrm{O}_{10}$ & 178,146 & Fucose-Galactose \\
& 2.7 & 231.0139 & -3.6 & $\mathrm{C}_{5} \mathrm{H}_{11} \mathrm{O}_{8} \mathrm{~S}$ & 151 & Xylitol sulphate \\
& 6.9 & 193.0339 & -0.9 & $\mathrm{C}_{6} \mathrm{H}_{9} \mathrm{O}_{7}$ & 149,121 & Glucuronic acid \\
& 7.1 & 261.0241 & -3.9 & $\mathrm{C}_{6} \mathrm{H}_{13} \mathrm{O}_{9} \mathrm{~S}$ & 165,129 & Mannitol sulphate \\
& 8.2 & 187.0952 & -1.8 & $\mathrm{C}_{9} \mathrm{H}_{15} \mathrm{O}_{4}$ & Nonanedioic acid \\
& 10.2 & 327.2205 & 3.4 & $\mathrm{C}_{18} \mathrm{H}_{31} \mathrm{O}_{5}$ & $309,291,229,211,171$ & Dihydroxy-oxo-octadecenoic acid \\
& 10.6 & 329.2343 & 1.5 & $\mathrm{C}_{18} \mathrm{H}_{33} \mathrm{O}_{5}$ & $311,293,211,171,139,127$ & Trihydroxyoctadecenoic acid \\
& 11.2 & 353.2354 & 2.6 & $\mathrm{C}_{20} \mathrm{H}_{33} \mathrm{O}_{5}$ & $317,273,235,127$ & Prostaglandin $\mathrm{F}_{2 \alpha}$ \\
\hline $\begin{array}{c}\text { Undaria } \\
\text { pinnatifida }\end{array}$ & 6.2 & 214.0154 & 0.7 & $\mathrm{C}_{5} \mathrm{H}_{10} \mathrm{O}_{7} \mathrm{~S}$ & 150,134 & Phosphatidic acid (34:1) \\
& 6.9 & 193.0339 & -0.9 & $\mathrm{C}_{6} \mathrm{H}_{9} \mathrm{O}_{7}$ & $149,121,105$ & Anhydrous xylitol sulphate \\
& 7.9 & 259.0149 & 2.5 & $\mathrm{C}_{6} \mathrm{H}_{11} \mathrm{O}_{9} \mathrm{~S}$ & 199,153 & Glucuronic acid \\
& 8.2 & 187.0952 & -1.8 & $\mathrm{C}_{9} \mathrm{H}_{15} \mathrm{O}_{4}$ & $169,125,123$ & Hexose sulphate \\
& 8.7 & 259.0149 & 2.5 & $\mathrm{C}_{6} \mathrm{H}_{11} \mathrm{O}_{9} \mathrm{~S}$ & 199 & Nonanedioic acid \\
& 10.2 & 264.9995 & 0.1 & $\mathrm{C}_{6} \mathrm{H}_{10} \mathrm{O}_{8} \mathrm{SNa}$ & 190 & Hexose sulphate \\
\hline & 10.7 & 325.1988 & -2.7 & $\mathrm{C}_{18} \mathrm{H}_{29} \mathrm{O}_{5}$ & $307,199,183,171,129$ & Sodiated fucose sulphate \\
\hline
\end{tabular}


Figure 1.
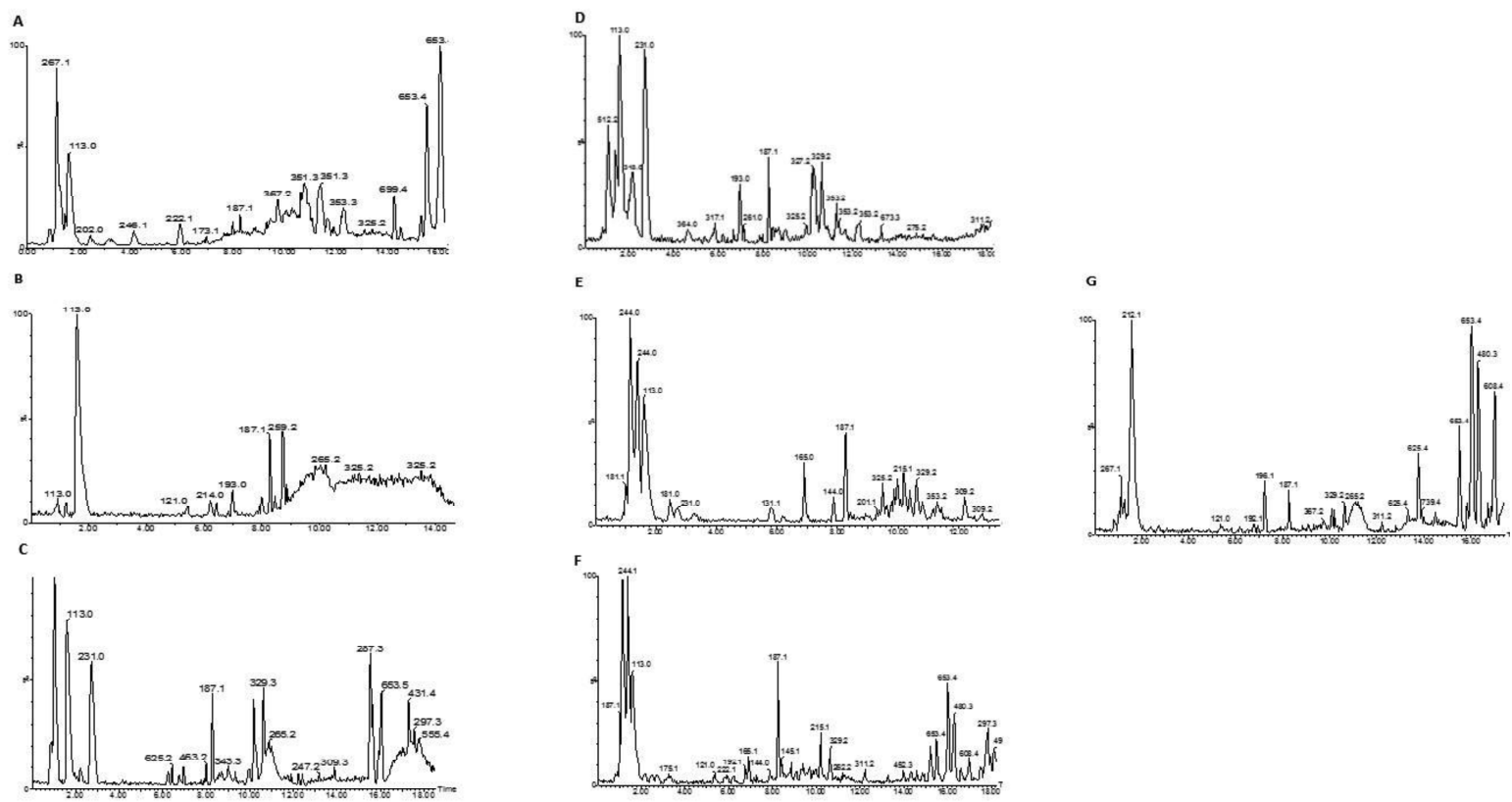
Figure 2.

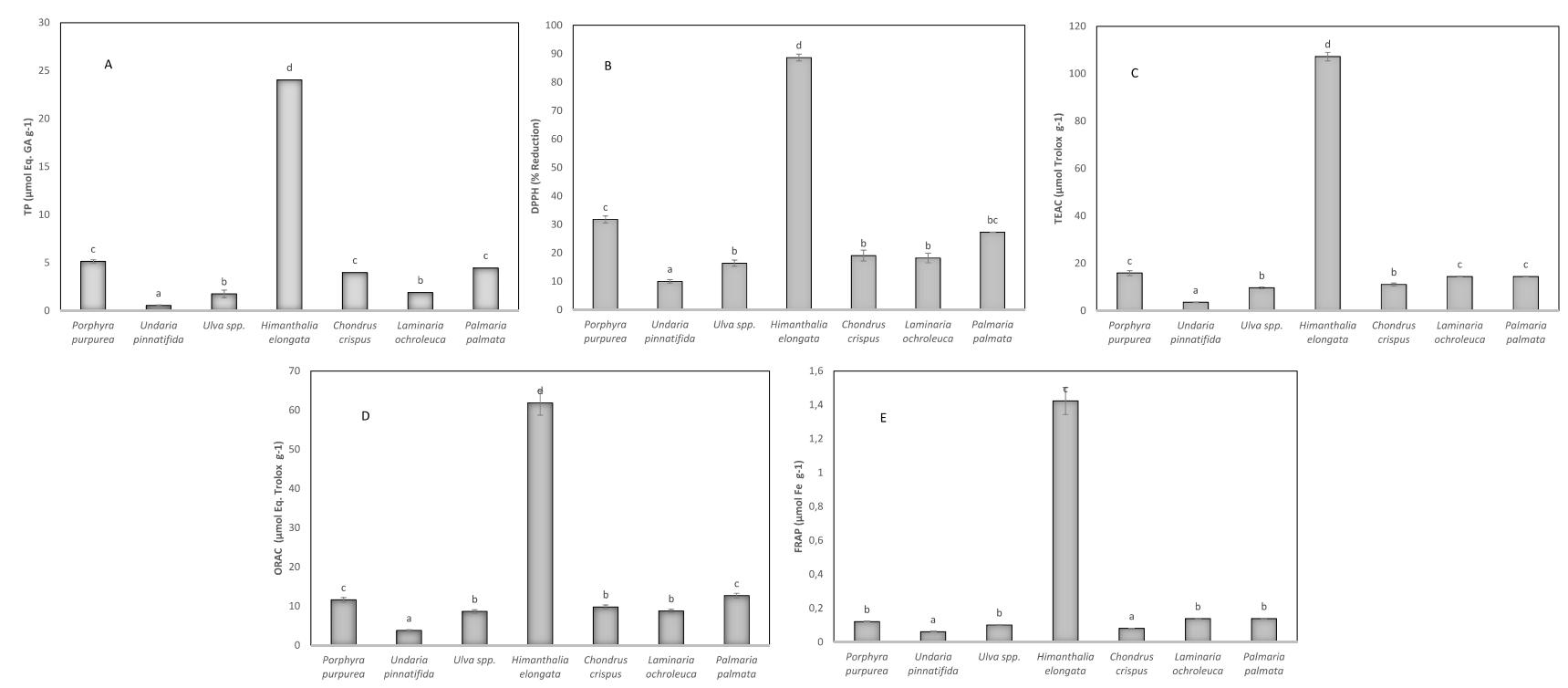


Figure 3.
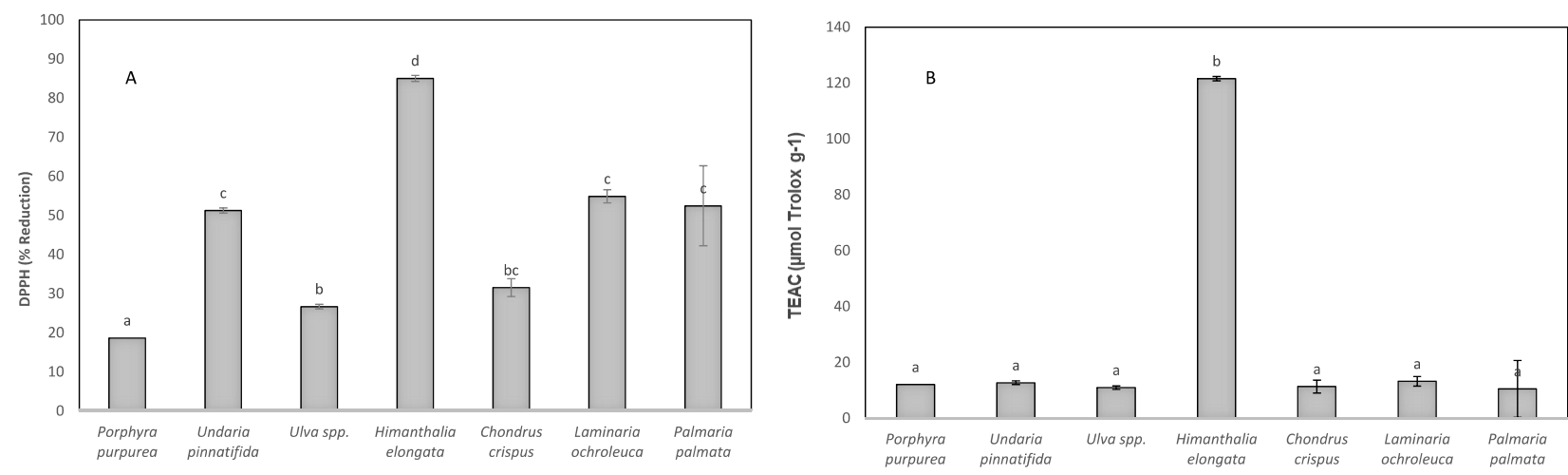
Figure 4.
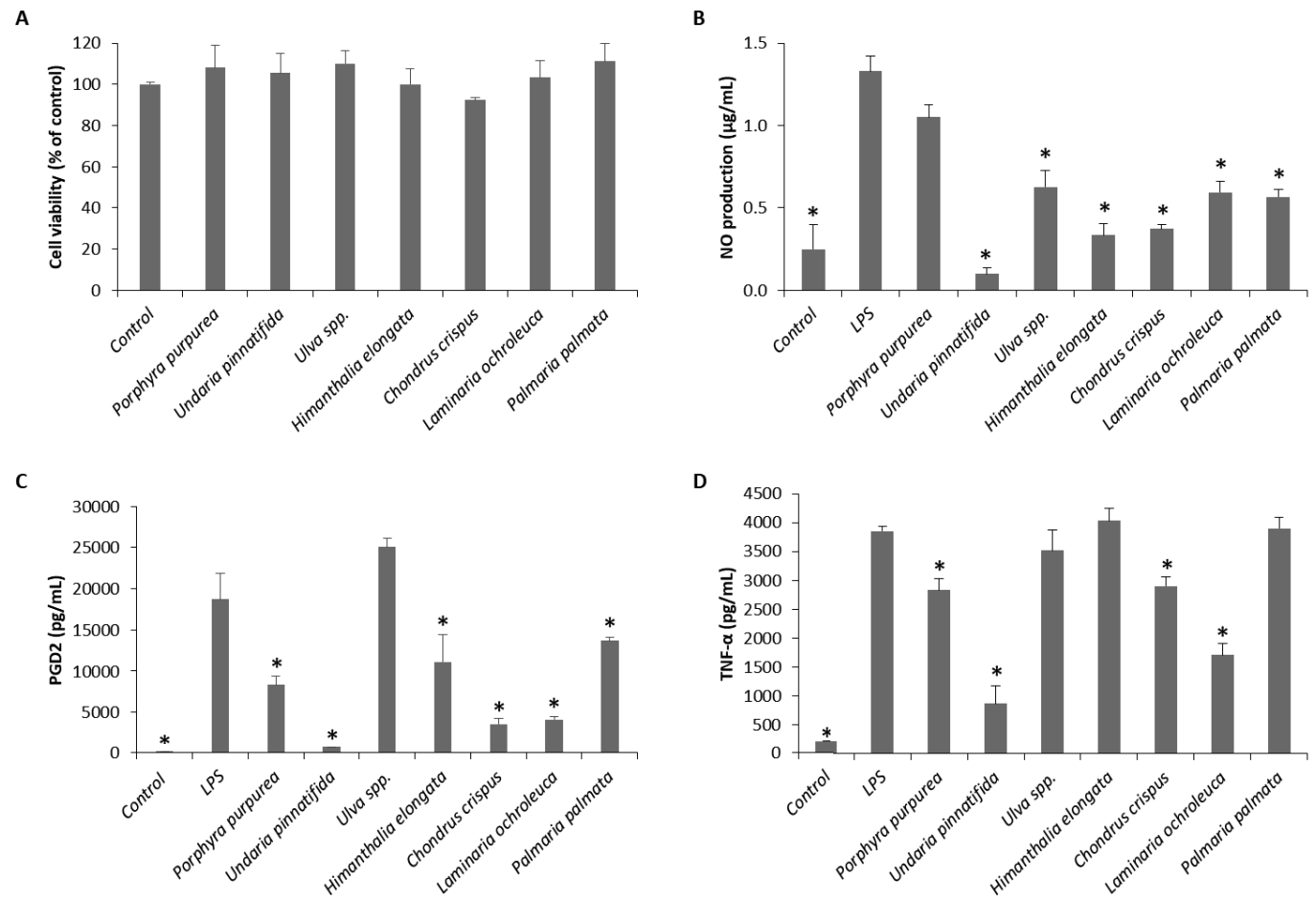
Figure 5.

\section{A}

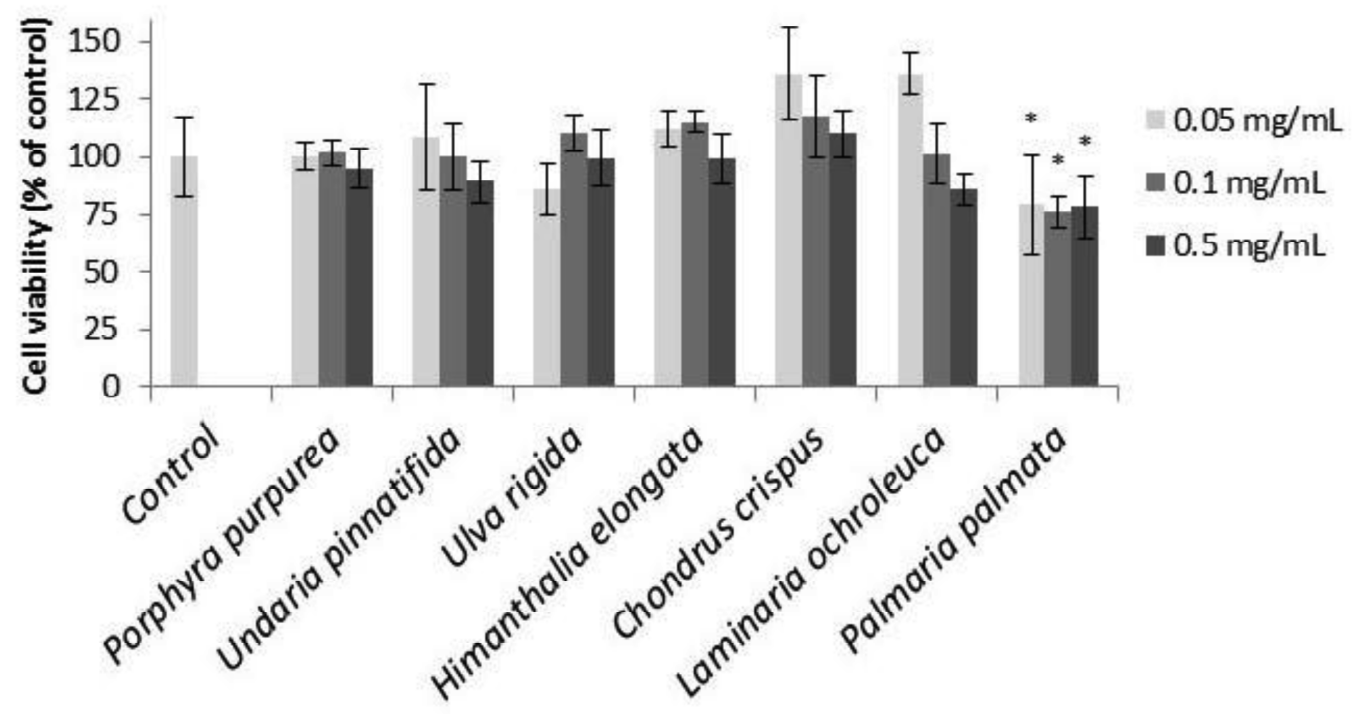

B

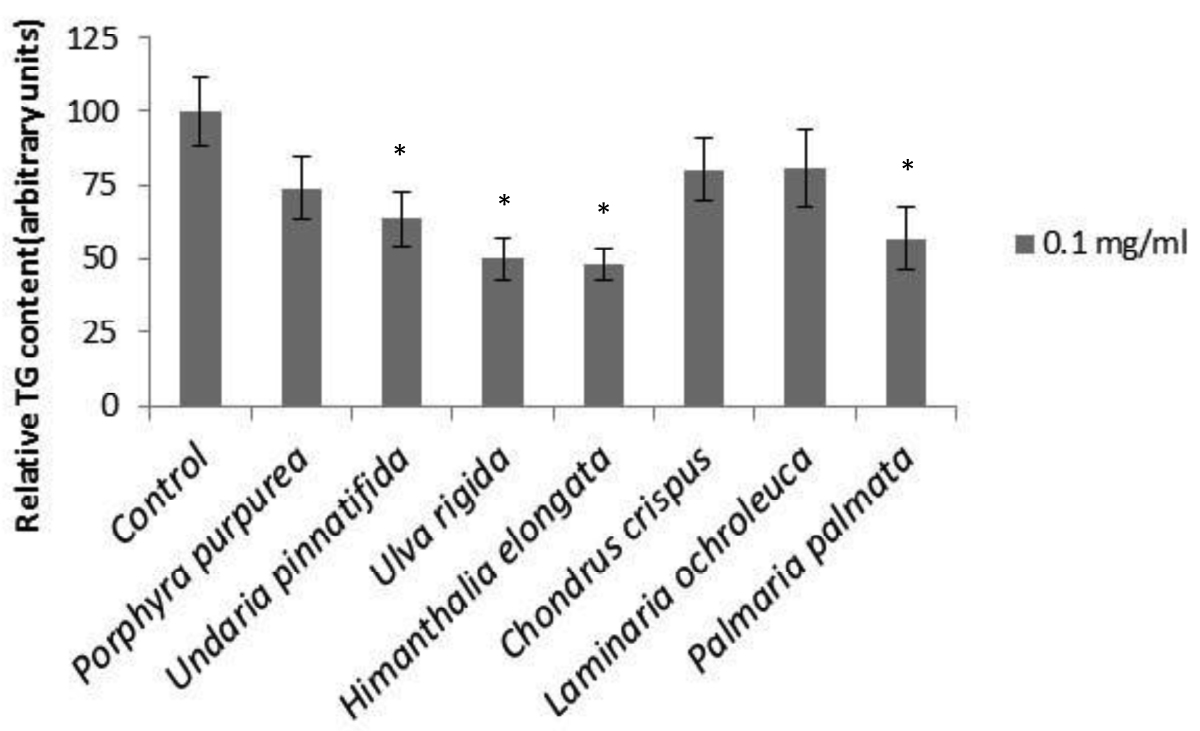



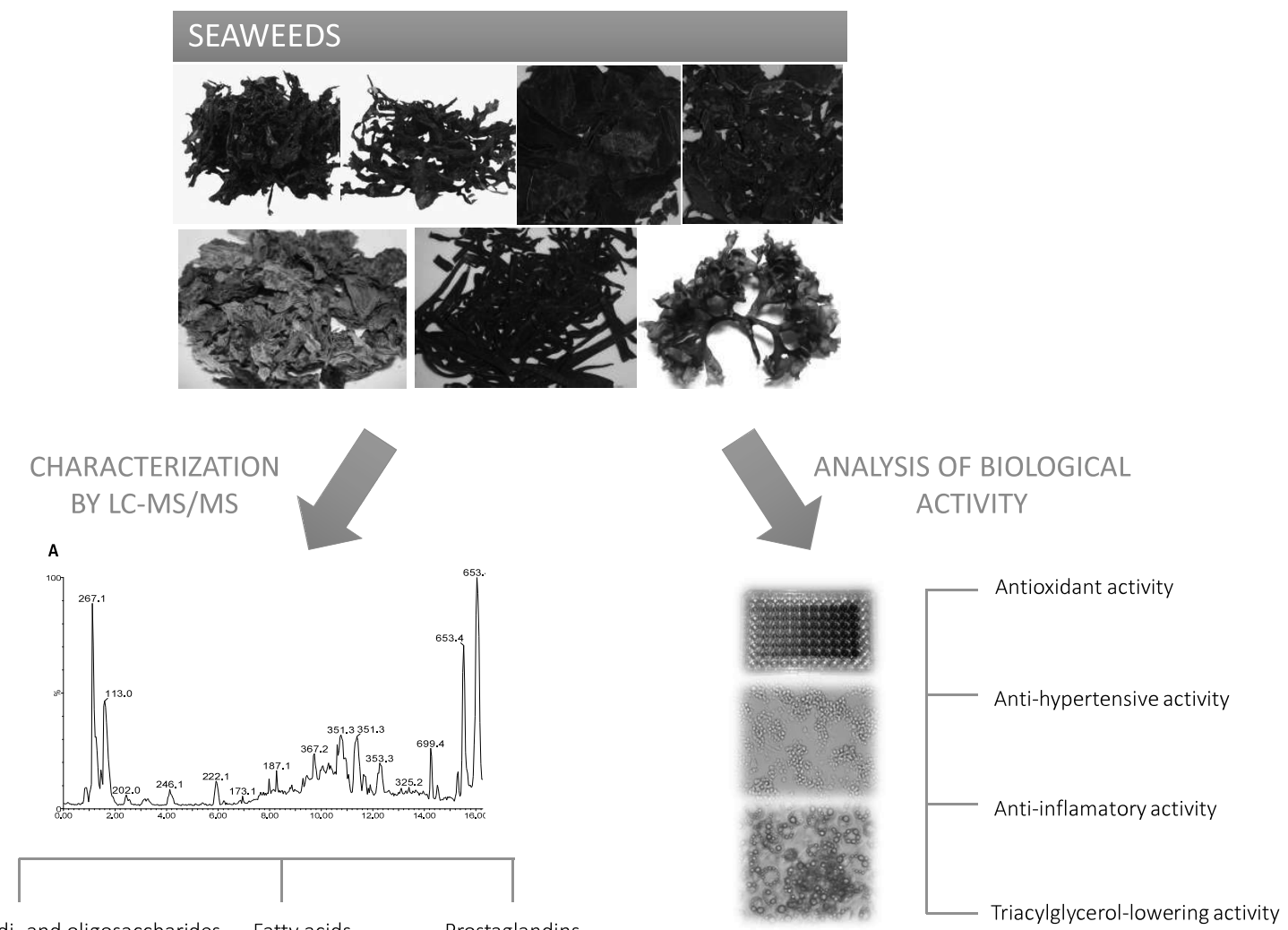